\title{
Diversificação e Competitividade nas Cooperativas Agropecuárias
}

\author{
Marco Aurélio Marques Ferreira \\ Marcelo José Braga
}

\begin{abstract}
Resumo
O objetivo deste trabalho foi avaliar a diversificação nas cooperativas agropecuárias e relacioná-la à melhoria da posição competitiva destas organizações. Como referencial teórico adotou-se a teoria do crescimento da firma, que fornece apoio à perspectiva da diversificação baseada no uso dos recursos. Utilizou-se o modelo econométrico Logit para determinar o impacto das variáveis associadas à decisão de diversificação. Para a coleta de dados utilizou-se a aplicação de questionários em amostra representativa de cooperativas distribuídas por diferentes regiões nos Estados de São Paulo e Minas Gerais. Os resultados indicaram que os condicionantes que se relacionam negativamente com a diversificação foram o resultado operacional por cooperado, o patrimônio total e o tipo de cooperativa. Por outro lado, aumentos na idade, no número de empregados e nas sobras operacionais influenciaram positivamente a diversificação nas cooperativas. Também se detectou correlação positiva entre a diversificação e as medidas de resultado e desempenho.
\end{abstract}

Palavras-chave: diversificação; cooperativas agropecuárias; estratégia competitiva.

\begin{abstract}
The objective of this study was to evaluate the diversification in the agricultural cooperatives, and to relate this strategy to the improvement of the organization's competitive position. As a theoretical referential, the theory of the growth of the Firm was adopted. It supports the resource-based as perspective. The econometric model Logit was used to determine the impact of the variables associated to the decision for diversification. For data collection, it was used a survey on a representative sample of cooperatives distributed in the States of Minas Gerais and São Paulo. The results showed that among the conditioners that are negatively related to diversification are the operational result by cooperative member, the total patrimony and the cooperative type. On the other hand, the increases in age, in employee numbers and in the operational leftovers also positively influenced the diversification in the cooperatives. Also, a positive correlation occurred between diversification and the measures of result and performance.
\end{abstract}

Key words: diversification; agricultural cooperatives; competitive strategy. 


\section{INTRODUÇÃO}

As cooperativas agropecuárias desempenham importante papel econômico e social, principalmente pelo fato de representarem, em muitas regiões, uma das poucas possibilidades de agregação de valor à produção rural, bem como da inserção de pequenos e médios produtores em mercados concentrados. De acordo com Pattison (2000), cerca de um terço da produção mundial de alimentos é governada pelas cooperativas.

De acordo com Sexton (1986), os benefícios das sociedades cooperativas estão associados à integração vertical que promove redução dos custos, por meio de melhor poder de barganha na aquisição dos insumos, às economias de escala, à melhoria da posição de barganha no mercado, em especial quando se trata de produtos perecíveis, aos ganhos de eficiência advindos da capacidade coordenadora das cooperativas e à redução dos riscos em ações conjuntas, comuns a esse tipo de empreendimento.

Do ponto de vista do bem-estar social, Sexton (1990), ao utilizar o modelo estrutura-conduta-desempenho, demonstrou também que as cooperativas agrícolas podem atenuar os efeitos adversos de uma estrutura de mercado concentrada. Mais tarde, este autor e colaboradores, ao adotarem como referencial a Teoria dos Mercados Contestáveis, mostraram que, à medida que uma cooperativa entra num mercado específico, ela é capaz de modificar o comportamento das firmas já existentes, fazendo com que estas passem a operar sob condições mais próximas à competição perfeita.

As alterações no ambiente político e econômico brasileiro, das décadas de 80 e 90 , vieram pressionar as cooperativas a se ajustarem no intuito de ampliar ou, pelo menos, manter sua participação no mercado. Nesse cenário, muitas cooperativas se endividaram, entraram em insolvência ou perderam participação no mercado. Outras, porém, se modernizaram administrativamente e sobressaíram competitivamente, com a preservação de sua identidade cooperativa.

Algumas dessas organizações conseguiram não apenas sobreviver, mas se destacar e aumentar a participação no mercado em que atuam, devido, sobretudo, a atitudes estratégicas do corpo administrativo, possibilitando-lhes distinguir-se no ambiente em que estavam insertas. A esse conjunto de atitudes denomina-se estratégia competitiva, e "sua meta para uma unidade empresarial é encontrar 
uma posição em que a organização possa melhor defender-se contra as forças que atuam sobre ela, ou influenciá-las em seu favor” (Porter,1986, p. 22).

Pode-se observar a existência de diversas estratégias que norteiam o ajustamento competitivo das cooperativas: integração vertical e horizontal; alianças estratégicas, como acordo ou parceria, holding e joint venture; concentração ou enfoque, como formação de centrais, união de cooperativas e fusões; e diversificação de negócios e de produtos.

A direção do processo de diversificação poderá seguir dois caminhos: diversificação concêntrica ou diversificação conglomerada ${ }^{(1)}$. Ocorre diversificação concêntrica, quando a base produtiva ou comercial da nova área de negócios da organização é altamente relacionada com as já existentes. Isso significa dizer que a empresa passa a produzir "novos produtos destinados a novos mercados, cuja produção ou comercialização guarda relacionamento estreito com a atividade anterior" (Tachizawa e Rezende, 2000, p. 81). Logo, cooperativas de processamento de leite que resolvem ampliar sua produção para bebidas lácteas, ou cooperativas de trigo que decidem partir para a comercialização de outros grãos correlacionados, são exemplos comuns desse tipo de diversificação.

A diversificação conglomerada ocorre, quando a nova área de negócios apresenta pouca ou nenhuma relação/sinergia com as áreas anteriores, no aspecto tecnológico ou comercial. Como exemplo, observa-se a abertura de supermercados, lojas de consumo, postos de gasolina e oficinas por cooperativas agropecuárias.

Como destaque em diversificação, cita-se a Cooperativa Agropecuária Holambra, que tem como setores-chaves: floricultura; pecuária (gado de leite, suínos, ovos e aves); e agricultura. Suas principais unidades estratégicas de negócio ${ }^{(2)}$ são: Bulbos (mudas), Veiling (leilões), Aves, Ovos, Citros, Cereais São Paulo, Cereais Rio Verde, Verduras, Suínos, Ração, Insumos (Santos, 1993).

No Paraná, o grande expoente de diversificação é a Cooperativa de Cafeicultores e Agropecuaristas de Maringá Ltda. - COCAMAR que, no final dos anos 60, percebendo os riscos inerentes à dependência de uma só atividade, inicia seu processo de diversificação, limitando-se, no começo, ao café e algodão e, mais tarde, a soja e trigo. Segundo Pinazza (1997), no início da década de 70 a situação era muito favorável à cotonicultura; entretanto a COCAMAR, solidária com a situação dos cooperados produtores de café, não se voltou exclusivamente ao negócio do algodão, mesmo sendo esse produto responsável por quase 70\% de sua base econômica. Decisões como essa sugerem a influência de outros fatores, além dos econômicos, na opção estratégica de diversificação. 
Conforme Rocha (1999), a COCAMAR trabalha com o que ela considera "pesos pesados"; são produtos que garantem, em conjunto, estabilidade à cooperativa, o que pode ser observado por meio da participação do setor de grãos, como soja, milho e trigo (62\%); algodão (16\%); e café (16\%); totalizando cerca de $90 \%$ do faturamento da cooperativa.

A Cooperativa Agropecuária de Rolândia, COROL, é outra que optou pela estratégia de diversificação, com vistas à diminuição dos riscos da monoatividade. Em razão dos problemas com a lavoura de café, enfrentados no início da década de 70, a COROL optou pela produção diversificada, por meio do processamento e da comercialização de outros grãos, como soja e milho. O objetivo, na época, era reduzir riscos e agregar valor ao produto de seus associados (Rocha, 1999).

Desse modo, é comum observar, em diversas cooperativas agropecuárias, a incorporação da estratégia de diversificação como meio de ajuste competitivo. Muitas dessas têm conseguido destaque no mercado em que atuam, o que demanda a investigação dos verdadeiros condicionantes e benefícios dessa estratégia.

Esse enfoque não ignora a influência dos fatores externos, visto que a organização é um sistema aberto, mas busca evidenciar a maior influência dos fatores internos como condicionantes da diversificação nas cooperativas agropecuárias, o que se dá em virtude das peculiaridades que as distinguem na apropriação e utilização de seus recursos. Assim, variáveis estruturais, tais como tamanho, tipo, idade da cooperativa e sobras operacionais, entre outros, poderão ser fatores decisivos na estratégia de diversificar as cooperativas.

Deste modo, o objetivo desse estudo foi avaliar os condicionantes estruturais da opção estratégica de diversificação em cooperativas agropecuárias e relacionar essa estratégia à melhoria da posição competitiva da organização.

\section{Referencial Teórico}

Conforme enfatiza Hendrikse e Van Oijen (2002), não existe literatura específica que trate da diversificação nas organizações cooperativa; porém existe uma abrangente literatura sobre diversificação com perspectivas teóricas ligadas ao Planejamento Estratégico, Teoria da Organização Industrial, Finanças, Teoria das Organizações e Marketing.

De acordo com os objetivos da empresa e a partir da perspectiva teórica, 
Montgomery (1994) classificou as análises que tentam explicar a diversificação em três grupos: poder de mercado, teoria da agência e uso dos recursos. Mais tarde, Hendrikse e Van Oijen (2002) acrescentaram dois outros enfoques: a teoria da contingência estratégica ${ }^{(3)} \mathrm{e}$ a redução de custo, devido à economia de escopo e à diminuição das transações; porém estes enfoques podem ser abordados no âmbito do uso de recursos, visto que lhes são diretamente relacionados.

De acordo com a perspectiva de poder de mercado, que se reporta à Teoria de Organização Industrial, as firmas diversificam os produtos em busca de mecanismos que lhes possibilitem exercer o poder de mercado, ou poder de conglomerado, conforme denominado por Hill (1985).

Estes mecanismos foram apontados por Ramanujan e Varaderajan (1989) como sendo subsídio cruzado ou preço predatório. No subsídio cruzado, as firmas usam os lucros provenientes de um mercado para suportar as atividades de preços predatórios em outro mercado. Outras formas, descritas por Montgomery (1994), seriam a tolerância mútua, quando os competidores se encontram em vários mercados, reconhecem sua interdependência, competindo menos vigorosamente, e compra recíproca, quando as grandes firmas diversificadas impedem a entrada de pequenas firmas competidoras no mercado.

Nesta perspectiva, dever-se-ia observar um relacionamento positivo entre diversificação e desempenho das firmas. Os estudos empíricos nesta linha, utilizando os instrumentais da Teoria da Organização Industrial, examinaram o relacionamento entre o desempenho da firma, medido em termos de retorno do patrimônio líquido ou do capital investido, e a estrutura da indústria, grau de concentração, economia de escala ou taxa de crescimento. A diversificação foi medida em termos de variáveis semelhantes ao Índice de Herfindahl. A maioria dos estudos encontrou relacionamento entre diversificação e desempenho das firmas neutro ou negativo ${ }^{(4)}$.

A perspectiva baseada na teoria da agência assevera que as firmas diversificam devido aos interesses pessoais de seus administradores. Esta teoria dedica à análise das relações entre o agente (administrador) e o principal (proprietário da firma). Por meio de contrato, é delegado ao agente a administração do empreendimento do principal. Embora exista esse contrato, o agente pode se ver motivado a agir em proveito próprio ou, simplesmente, contrariar os objetivos do principal, diferentemente do estabelecido previamente. Assim, os agentes investem em projetos de diversificação, visando a futuros aumentos de salários e à redução de risco de emprego, na medida em que isso exige que a firma aumente a demanda por suas habilidades particulares. 
A agravante está no fato de nenhum contrato ser perfeito e de seu desenho, readequação e monitoramento gerarem elevado custo. Nisso consiste o problema de agência: definir os sistemas de benefícios que permitam que os objetivos dos agentes convirjam para os objetivos do principal e estabelecer uma governança corporativa eficiente do ponto de vista dos interesses do principal.

No centro da teoria está o pressuposto da informação assimétrica, ou seja, o agente possui maior conhecimento do negócio do que o principal, estando apto a agir oportunistamente em qualquer momento (Nilsson, 1999). Na literatura, esta questão é tratada como perigo moral, moral hazard.

Aron (1988) desenvolveu um modelo que trata da diversificação da firma, baseado no problema da agência. Os resultados indicaram que a diversificação foi a alternativa adequada para mitigar o problema do perigo moral.

A partir deste ponto de vista, pode-se prever um resultado negativo entre a diversificação e o desempenho da firma, conforme se encontra em Denis, Denis e Sarin (1997).

A terceira perspectiva argumenta que as firmas, tendo excesso de capacidade em recursos produtivos, poderão utilizá-los em novos negócios, via impossibilidade de crescimento por meio da expansão. Assim, a diversificação seria uma alternativa para que a firma empregue lucrativamente os seus recursos. Os trabalhos de Edith Penrose, em Teoria do Crescimento da Firma (Penrose, 1959), forneceram a base para esta visão.

Todavia existe uma justificativa para a influência do tamanho da organização na decisão de diversificar: Penrose (1959) estima que é porque as maiores empresas detêm maiores recursos produtivos e acesso a processos tecnológicos mais complexos e menos padronizados do que pequenas empresas.

Para Teece (1982), as economias de escopo de Penrose não teriam efeito sobre o tamanho da firma, se os recursos não-utilizados fossem eficientemente vendidos no mercado. Se a firma conseguisse transferir os seus ativos físicos sem custos irrecuperáveis, a racionalidade para diversificação deixaria de existir.

Barni e Brandt (1992) constataram que as cooperativas têm diversificado suas atividades, operando com mais de uma unidade de produção, incorporando setores de consumo, postos de venda ou unidade de processamento de produtos ou insumos, por razões muito objetivas, como as seguintes: (a) busca de ganhos de eficiência, 
mediante a redução de custos de transporte e custos administrativos; (b) obtenção de maior parcela de mercado, atuando competitivamente; e (c) por aspectos circunstanciais, em que procuram atender às exigências dos associados e/ou do mercado comprador.

Segundo esses autores, cooperativas diversificadas que comercializam maior número de produtos e/ou serviços, dentro de certos limites, podem apresentar custos unitários menores que as cooperativas especializadas. Isso evidencia a menor ociosidade dos fatores, com melhor aproveitamento de insumos públicos ou partilháveis, sendo desse modo outro fator de condução a diversificação em detrimento da especialização. Assim, com menor ociosidade de fatores, melhor uso de insumos e maior aproveitamento dos recursos, a firma obtém economias de escopo ${ }^{(5)}$, o que tem levado à preferência pela multiprodução em organizações cooperativas.

Para Trechter (1996), fatores internos, como melhoria do desempenho financeiro, tamanho da cooperativa e aversão a risco, exercem mais influência na diversificação do que os fatores externos, como redução da participação no mercado e aproveitamento de oportunidades existentes.

A visão de recursos sugere que o volume de lucros e o tamanho da diversificação de uma firma são funções do seu estoque de recursos partilháveis ou nãoespecíficos.

Para Montgomery (1989), fatores menos específicos podem fornecer a base para uma diversificação mais ampla pela empresa, mas implicam baixos níveis de retornos, pois são amplamente ofertados no mercado. Para firmas com recursos menos específicos, os lucros podem ser maximizados com alto nível de diversificação, enquanto uma firma com mais recursos específicos pode obter lucros maiores com menos diversificação.

\section{Metodologia}

Considerando os aspectos apresentados na seção anterior, optou-se pelo enfoque teórico, baseado no uso de recursos, para explicar a diversificação nas cooperativas agropecuárias. Assim, variáveis estruturais, como tamanho, tipo, idade da cooperativa, sobras operacionais, patrimônio total, entre outras, são testadas no intuito de identificar sua relação com o fenômeno em estudo. 


\section{Condicionantes da Estratégia de Diversificação}

Trechter (1996) utilizou o Modelo Logit para analisar os fatores associados com diversificação nas cooperativas agropecuárias de Wisconsin, nos Estados Unidos. Este modelo se apresentou como importante ferramenta na previsão de diversificação, não somente por determinar as variáveis que estão mais associadas à decisão de diversificar, mas sobretudo por dimensionar o impacto dessas variáveis sobre a opção estratégica de diversificar.

Desse modo, a inclusão de um modelo econométrico no estudo foi motivada pela necessidade de relacionar a diversificação às variáveis estruturais apresentadas no referencial teórico. O Logit pertence à classe dos modelos econométricos em que a variável explicada é na verdade uma variável qualitativa ou, sendo quantitativa, dela apenas se pode observar uma manifestação de caráter qualitativo (Oliveira, et alii., 1997).

De acordo com Gujarati (2000), nesses modelos a variável dicotômica é uma variável dummy, que assume os valores 0 ou 1 , o que na análise em estudo representa: 0 , quando a cooperativa não é diversificada; e 1 , quando a cooperativa apresenta diversificação de negócios ou produtos.

No modelo Logit, define-se $P_{i}$ como a probabilidade de uma cooperativa diversificar. Essa probabilidade é determinada por vários fatores representados por $Z_{i}=X_{i} \beta$. Dentre esses fatores tem-se a idade da cooperativa, o número de empregados, as sobras operacionais, o tipo de cooperativa, o patrimônio total e o resultado operacional por cooperados. Por meio da obtenção dos coeficientes dessas variáveis explicativas e do cálculo dos seus efeitos marginais, pode-se precisar a variação na probabilidade da variável dependente, calculada no seu ponto médio, pela variação das variáveis explicativas descritas no modelo, o que é realizado pela equação abaixo:

$\operatorname{EMX}_{K}=\beta_{k}\left(1-P^{*}{ }_{i}\right) P^{*}{ }_{i}$

Onde, $\beta_{k}$ é o coeficiente da variável explicativa $X_{k}, P^{*}{ }_{i}$ é a estimativa da probabilidade de ocorrência de diversificação e $\left(1-P^{*}{ }_{i}\right)$ é a estimativa da probabilidade de não-diversificação (Gujarati, 2000).

\section{Variáveis do Modelo}

Como não era possível mensurar precisamente todos os fatores relacionados à 
decisão de diversificação, foram definidas variáveis que servissem de proxy para mensurar o impacto dessa estratégia.

Diversificação (Y): constatada com informações obtidas por meio da coleta de dados. Desse modo, a cooperativa foi considerada diversificada, recebendo $\mathrm{Y}=1$, quando apresentou negócio(s) diferente(s) do negócio principal da cooperativa ou apresentou produtos de base comercial ou base produtiva, diferente do produto principal da cooperativa, desde que estes representassem, conjuntamente, mais de $10 \%$ da receita bruta da cooperativa( ${ }^{(6)}$. Nos casos contrários, a cooperativa foi considerada não-diversificada, sendo $\mathrm{Y}=0$.

Convencionou-se como base produtiva aquele conjunto de bens de capital, fatores de produção, insumos e recursos humanos destinados à produção de um ou vários produtos que guardam alta relação tecnológica entre si. A base comercial diz respeito aos recursos e às tecnologias empregadas na comercialização de um ou vários bens específicos, com alto grau de sinergia. A sinergia é definida aqui como alta relação em aspectos de armazenagem, transporte, recursos humanos e logística, como um todo.

Número de empregados (CP): refere-se ao número de cooperados pertencentes à estrutura funcional da cooperativa. Esperava-se que as cooperativas que dispunham de maior número de cooperados fossem mais diversificadas, tendo em vista a possibilidade da diversificação ser uma forma de agregar valor ou comercializar a diversificação primária, ou seja, aquela derivada da própria produção diversificada do quadro social.

Faturamento bruto (FB): medido em milhões de reais (R\$), registrados no balanço contábil referente ao período de 01/01/2000 a 31/12/2000. Esperava-se que cooperativas com maior faturamento bruto fossem mais propensas a investimentos em novos produtos e negócios.

Tipo de cooperativa (TP): essa variável, de aspecto qualitativo (dummy), representa o papel das cooperativas dentro do agronegócio. Assim, convencionouse dividi-las em dois grupos, atribuindo-lhes valores 1 ou 0 , conforme seu papel principal, apresentado em seguida.

Cooperativas de processamento e comercialização $(\mathbf{T P}=1)$ : equivalem àquelas cooperativas que têm como papel principal receber e processar o produto dos cooperados, assim como comercializar esses produtos no mercado.

Cooperativas de serviços e repasse de produção $(\mathrm{TP}=0)$ : equivalem 
àquelas cooperativas agropecuárias que têm como papel principal a disponibilização de insumos e serviços para os cooperados e/ou apenas recebem e repassam a produção do cooperado para uma central ou empresa comercial. Inicialmente, esperava-se uma relação positiva entre diversificação e cooperativas $(T P=0)$. Isso porque, na literatura, a diversificação é tida como uma alternativa diante da impossibilidade de crescer via expansão.

Patrimônio total (PT): medido pela soma, em milhões de reais ( $\mathrm{R} \$$ ), de todos os ativos registrados no balanço contábil do exercício referente ao período de $01 /$ 01/2000 a 31/12/2000. Esperava-se uma relação negativa entre patrimônio total e diversificação, uma vez que a maior parte desse patrimônio é notoriamente representada por ativos imobilizados, o que representa um desestimulante à diversificação, ou, visto de outra forma, como estimulante à especialização.

\section{Diversificação e Competitividade}

\section{Associação entre Diversificação e Medidas de Resultado}

O coeficiente de correlação simples ( $r$ ) é uma medida de associação entre variáveis quantitativas, cujo objetivo é mensurar e determinar o sentido de relação entre variáveis (Barbetta, 2001). Assim, de posse das cooperativas diversificadas, pertencentes à amostra, foi calculado o coeficiente de correlação entre grau de diversificação e medidas de resultado, e desempenho nas cooperativas agropecuárias em estudo.

O objetivo era desvendar a relação existente entre diversificação e as seguintes medidas de resultado e desempenho: Faturamento Bruto (FB), Ativo Total (AT), Resultado Operacional (RO) e Sobras Operacionais (SO).

Para aprofundar a relação entre diversificação e posicionamento competitivo, foi calculado, também, o coeficiente de correlação por postos $\left(r_{p}\right)$ entre o grau de diversifação e a competitividade.

O $r_{p}$ utiliza-se apenas da ordenação dos valores na análise de associação das variáveis, sendo utilizado quando os dados de algumas das variáveis em estudo se mostram com distribuição muito assimétrica ou com valores discrepantes.

\section{Fonte de Dados e Área do Estudo}

O estudo foi realizado com amostra representativa de 64 cooperativas localizadas 
em 12 regiões, pertencentes aos Estados de Minas Gerais e São Paulo. Os dados foram coletados por meio de questionários enviados às cooperativas, entre os meses de agosto e setembro de 2001. A significativa abrangência da pesquisa, que procurou contemplar todas as regiões dos Estados em análise, contribuiu bastante para eliminar o viés decorrente de maior influência de uma região ou cidade, especificamente.

\section{Resultados e Discussão}

\section{Diversificação de Negócios}

Observou-se que 47,7\% das cooperativas agropecuárias em estudo apresentam diversificação de negócios. Na investigação dos fatores que poderiam estar estimulando essa busca por novos negócios, foi possível perceber que 30,3\% das cooperativas, pertencentes à região pesquisada, apresentaram baixos retornos ou prejuízos nos seus negócios. Esse percentual é relativamente alto e pode representar importante estímulo à busca da diversificação de negócios, quando esta for encarada como alternativa diante dos prejuízos e baixos retornos nas atividades principais.

Corroborando essa tese, verificou-se que 47,4\% dessas cooperativas apresentam esses baixos retornos ou prejuízos justamente no seu negócio principal, e mais $10,5 \%$ apresentam baixos retornos ou prejuízos em ambos os negócios. Somente 42,1\% apresentam prejuízos ou baixos retornos em negócios secundários e/ou complementares à atividade principal da cooperativa.

Desse modo, o alto índice de cooperativas com prejuízo ou baixo retorno relacionados à atividade principal parece estimular a diversificação como nova postura estratégica que visa a minimizar riscos e impulsionar receitas.

\section{Diversificação de Produtos}

Cerca de $45,8 \%$ das cooperativas pertencentes ao estudo apresentam diversificação de produtos. Destas, 30,8\% têm entre 10\% e 30\% do seu faturamento bruto originado de produtos fora de sua base produtiva ou comercial principal, ou seja, de linha de produção diversificada. Outros 38,4\% das cooperativas têm mais de $30 \%$ do seu faturamento bruto originado de produtos diversificados. Assim, eliminando-se 5,2\% não-respondentes, é possível notar que 
apenas 25,6\% têm menos de $10 \%$ do seu faturamento advindo de produtos de base produtiva ou comercial diferente, sendo consideradas, portanto, nãodiversificadas.

\section{Razões que Têm Levado as Cooperativas a Diversificar}

Conforme apontado pela literatura, os motivos que levam à decisão estratégica de diversificar podem ser classificados em razões de natureza interna e razões de natureza externa. As Figuras 1 e 2, apresentadas abaixo, ilustram a participação desses fatores na escolha dessa estratégia, baseando-se no percentual de observação de sua incidência nas cooperativas que compõem a amostra.

\section{Figura 1: Fatores Internos que Têm Condicionado a Estratégia de Diversificação}

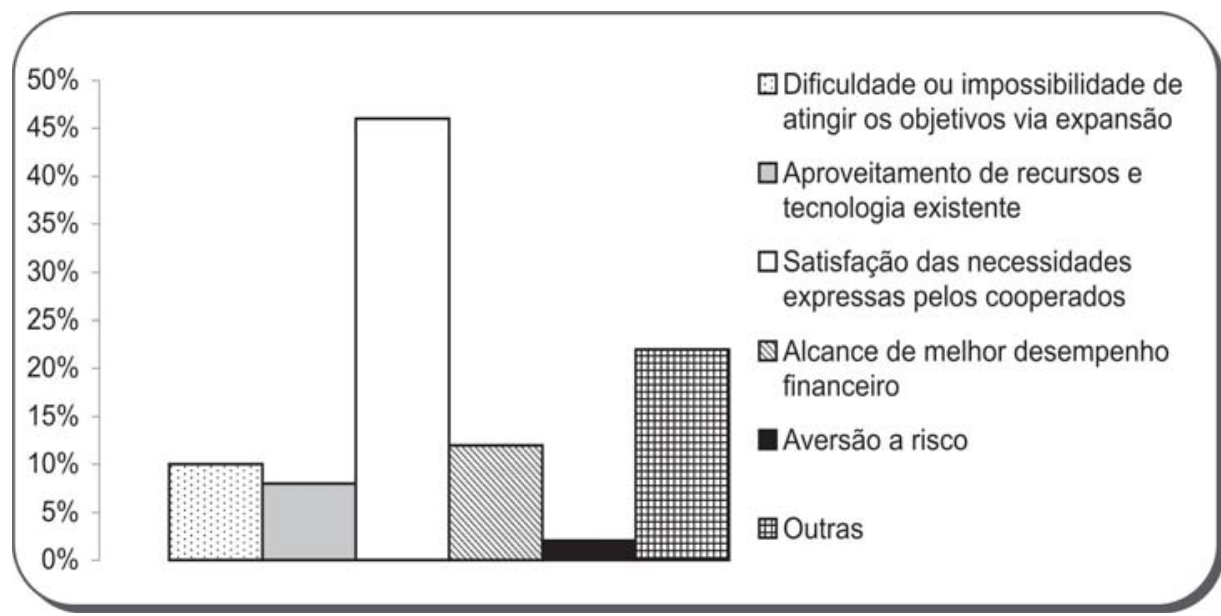

Fonte: resultados da pesquisa.

Dentre os fatores internos, esperava-se que a aversão ao risco apresentasse maior influência na opção de diversificar, visto que, na literatura, diversificação é apresentada como alternativa de diminuição de riscos, além do fato de que trabalhos como os de Cardinal e Opler (1995) e Trechter (1996) desvendaram a significativa influência dessa variável na opção estratégica de diversificar. Ainda assim, conforme indicam os resultados, a diversificação está mais fortemente associada à satisfação dos interesses dos cooperados e à busca de melhor desempenho financeiro. 


\section{Figura 2: Fatores Externos que Têm Condicionado a Estratégia de Diversificação}

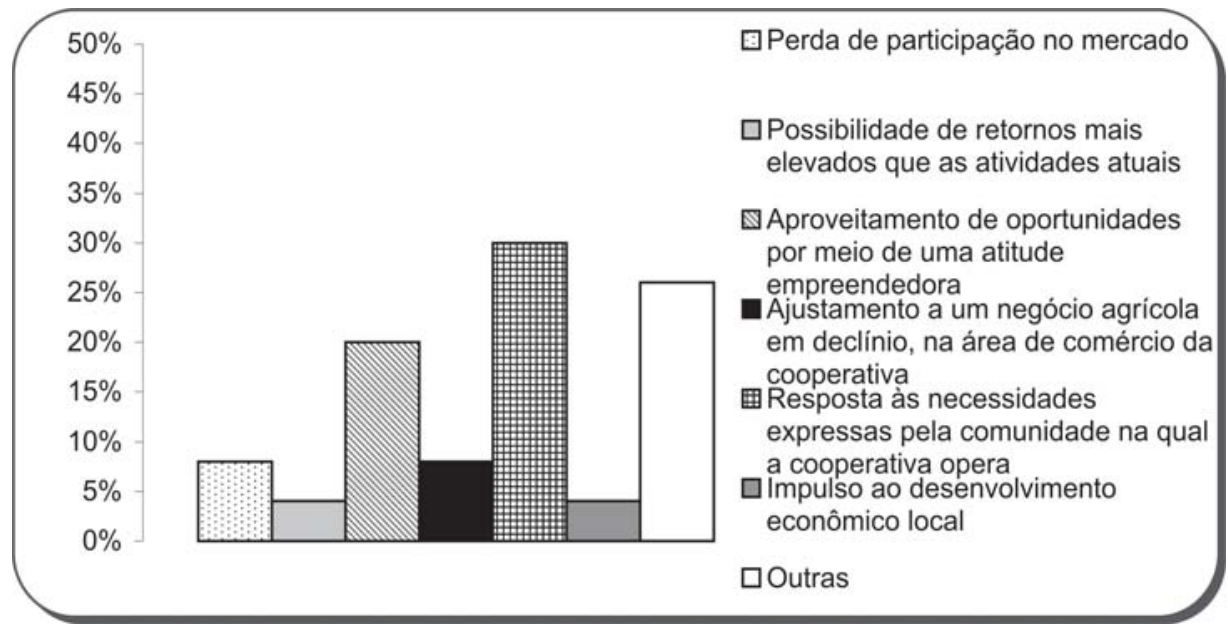

Fonte: resultados da pesquisa.

A principal razão externa apontada como motivadora da diversificação foi a satisfação das necessidades expressas pela comunidade em que a cooperativa opera, com $30 \%$ das respostas, o que revela o importante papel social que as cooperativas ainda representam em diversas regiões, principalmente nas comunidades rurais. Em algumas regiões, as cooperativas são a única forma que os produtores têm de comercializar sua produção e de adquirir os insumos agrícolas, além do fato de serem, em muitas localidades, a maior força empregadora, o que, por si, destaca o seu papel no desenvolvimento regional.

A possibilidade de retorno mais elevado também demonstra importância como razão motivadora, visto que a linha de negócios e produtos diversificados foi responsável pelo equilíbrio financeiro de diversas das cooperativas que apresentaram prejuízos e baixos retornos no seu negócio principal no triênio 1998, 1999 e 2000.

Ressalta-se que a identificação dessas razões permite aos administradores classificá-las como pontos fracos, pontos fortes, ameaças e oportunidades, o que contribui qualitativamente para a formulação do planejamento estratégico em cooperativas, bem como para a intervenção participativa de gestores nas políticas voltadas ao setor. 


\section{Sentido da Diversificação}

Ao investigar o grau de relação entre a base produtiva e comercial dos novos negócios e produtos com a atividade principal da cooperativa, constatou-se que em 58,5\% das cooperativas existe alta relação; em 20,8\%, constatou-se pouca relação; e em apenas 1,9\% não se observou nenhuma relação. Cerca de $17 \%$ das cooperativas declararam que alguns dos seus novos negócios ou produtos mantêm alta relação, enquanto outros mantêm pouca relação com a base produtiva ou comercial principal. O restante não manifestou a condição da cooperativa.

Assim, é possível constatar que a maior parte das cooperativas diversificadas (58,5\%) apresenta diversificação concêntrica, isto é, diversificam suas atividades, procurando manter alta relação com as já existentes, principalmente a atividade principal.

Por outro lado, 22,7\% das cooperativas diversificadas se dedicam à diversificação conglomerada, ou seja, mantêm pouca ou nenhuma relação entre os negócios atuais e os novos negócios.

Outros 17\% das cooperativas não determinam o sentido de sua diversificação, sendo possível observar, em certos casos, a utilização da metodologia tentativae-erro na incorporação de novos negócios e produtos. Nesses casos, a conseqüência é a formação de vários conglomerados diversificados, o que poderá resultar perda de sinergia ou comprometimento da capacidade administrativa ao longo dos anos.

A diversificação concêntrica é preferencialmente recomendada, tendo em vista que maior relação entre os negócios da cooperativa propicia maior eficiência no aproveitamento dos recursos comuns, o que poderá permitir o aproveitamento de economias de escopo. As economias de escopo em cooperativas agropecuárias foram verificadas nos trabalhos de Barni e Brandt (1992) e Cruz Filho et. al. (1988).

Assim, é possível dizer que, quanto maior o grau de relação dos negócios e produtos existentes, maiores serão as possibilidades de existência de economias de diversificação nas cooperativas agropecuárias.

Outro fator positivo está relacionado ao know how adquirido, uma vez que determinadas atividades demandam elevado tempo até que a empresa tenha domínio sobre elas.

A diversificação concêntrica apresenta sinergia de marketing, principalmente 
no que diz respeito ao aproveitamento do lugar que a organização já conquistou na mente do consumidor. Dessa forma, se a cooperativa é tida pelo cliente como excelente na área de alimentos, seria mais sensato diversificar no mesmo âmbito do negócio, caeteris paribus, do que se deslocar em direção a negócios pouco relacionados, o que poderia gerar certa resistência por parte do consumidor. Além disso, o aproveitamento da marca, em muitos casos, se restringe a um mesmo negócio; e o esforço em marcas diferentes gera elevado dispêndio financeiro. Assim, parece coerente o fato de que a maior parte das cooperativas da região em estudo tenha adotado a diversificação concêntrica.

\section{Condicionantes da Estratégia de Diversificação}

A inclusão do modelo Logit neste estudo visa não apenas identificar mas quantificar o impacto das variáveis que condicionam a opção de diversificação nas cooperativas agropecuárias, o que é realizado pela análise do efeito marginal.

As variáveis descritas pelo modelo [idade das cooperativas (ID), número de empregados (EP), tipo de cooperativa (TP), sobras operacionais (SO) e resultado operacional por cooperado (RO)] foram capazes de prever $80 \%$ das cooperativas agropecuárias diversificadas e 74\% das cooperativas não-diversificadas. Desse modo, o poder total de previsão do modelo é de $77,5 \%$, o que caracteriza sua eficiência na análise do fenômeno em estudo.

Por intermédio do Quadro 1 podem ser observadas as variáveis utilizadas no modelo econométrico, com as respectivas significâncias, apuradas pelo teste de estatística Z. É possível observar também o efeito marginal das variáveis ID, EP, TP, PT, SO e RO sobre a probabilidade de diversificação nas cooperativas agropecuárias.

\section{Quadro 1: Variáveis Condicionantes da Diversificação nas Cooperativas de MG e SP - 2001}

\begin{tabular}{lllll}
\hline Variável & Coef. Estimado & Efeito Marginal & Estatística - Z & Probabilidade \\
\hline C & $-0,21406300$ & $-0,0533191820$ & $-0,26995$ & 0,787 \\
ID & 0,03796200 & 0,0094556406 & 1,97398 & 0,048 \\
EP & 0,01415800 & 0,0035264991 & 2,30703 & 0,021 \\
TP & $-1,33885800$ & - & $-1,68237$ & 0,092 \\
PT & $-0,00000009$ & $-0,0000000229$ & $-2,24024$ & 0,025 \\
SO & 0,00000287 & 0,0000007149 & 1,81282 & 0,061 \\
RO & $-0,00020400$ & $-0,0000508127$ & $-2,73620$ & 0,006 \\
LR & 29,71 & & & \\
statistic & & & & \\
\hline
\end{tabular}

Fonte: resultados da pesquisa. 
Os coeficientes estimados, por meio do modelo, apresentaram ajustamento satisfatório. O teste de razão de verossimilhança apresenta-se significativo a 1\%, indicando que as variáveis incorporadas têm considerável poder para explicar o fenômeno em estudo.

Das variáveis, SO e TP apresentam-se significativas a menos de $10 \%$. As demais, ID, EP, PT e RO, apresentam-se significativas a menos de $5 \%$. As variáveis apresentaram resultados compatíveis com o esperado, sendo os sinais coerentes com a literatura pertinente.

Observou-se que a idade afeta positivamente a probabilidade de a cooperativa diversificar; desse modo, pode-se dizer que, quanto maior a idade, maior a probabilidade de a cooperativa diversificar. Assim, um aumento de 10 anos na idade da cooperativa (ID) aumenta em 0,095 a sua probabilidade de diversificação.

A maior incidência de diversificação entre as cooperativas mais velhas, provavelmente, remonta ao período entre as décadas de 60 e 80 , quando essas viviam sob a tutela do Estado, recebendo elevados subsídios financeiros, destinados à produção e comercialização de produtos agrícolas. Diante da abundância de recursos, as cooperativas agropecuárias daquela época tiveram condições financeiras para incorporar novos produtos e negócios no seu portfólio.

Por outro lado, observa-se que as cooperativas constituídas na segunda metade da década de 80 não tiveram a mesma sorte, uma vez que vivenciaram a crise da redução dos subsídios agrícolas. Elas tiveram de conviver, ainda, com a queda dos níveis de preços dos produtos agrícolas durante as décadas de 80 e 90 e as crescentes exigências de investimento em tecnologias de maior valor agregado, ambos agindo como inibidores das estratégias de crescimento via diversificação.

Observa-se que o número de empregados da cooperativa afeta positivamente a probabilidade de ela diversificar; dessa forma, quanto maior o quadro de empregados, maiores serão as possibilidades de a cooperativa diversificar-se. Assim, um aumento de 10 empregados na cooperativa aumenta em 0,035 a sua probabilidade de diversificação.

Em conformidade com a teoria do crescimento da firma, espera-se que as empresas que dispõem de melhor estrutura de recursos humanos (gerenciais, diretivos e operacionais), tenham maior possibilidade de diversificar; daí a origem de relação positiva constatada entre número de empregados e diversificação nas cooperativas agropecuárias.

Trechter (1996) também observou efeito marginal positivo entre o tamanho da 
cooperativa e a probabilidade de ela ser diversificada, em pesquisa realizada nas cooperativas agropecuárias de Wisconsin, nos Estados Unidos.

Isso evidencia a influência do porte da organização na diversificação em cooperativas agropecuárias. A título de ilustração, das 15 maiores cooperativas agropecuárias de Minas e São Paulo, 7 estavam presentes na amostra de pesquisa desse trabalho; destas, apenas 2 não eram diversificadas.

Quanto ao tipo de cooperativa, definido pelo corte analítico entre cooperativas de serviços e repasse de produção $(\mathrm{TP}=0)$ e cooperativas de processamento e comercialização (TP = 1), o que se observa é a menor probabilidade de diversificar entre as cooperativas de processamento e comercialização, uma vez que a variável tipo (TP) se relaciona negativamente com a diversificação.

A explicação pode estar na pressão competitiva exercida pelo mercado, principalmente no que diz respeito a necessidades de mudanças e exigências na capacidade de inovação. Acredita-se que o aumento da competitividade empresarial, ao longo dos anos, tenha levado as cooperativas a rever constantemente suas estratégias como alternativa de crescimento ou sobrevivência.

Observa-se relação negativa entre o patrimônio total (PT) e a diversificação nas cooperativas agropecuárias. Assim, um aumento de R\$100.000,00 no patrimônio total das cooperativas resulta na diminuição da probabilidade de diversificar em 0,0023.

Conforme já mencionado, existem fatores típicos que norteiam a tomada de decisão estratégica em cada organização de acordo com sua estrutura e seus recursos. Uma cooperativa com alto investimento em ativo fixo estará mais propensa a atividades que incorporem esse ativo. Outra, com ativos de elevada liquidez, poderá aventurar-se em direção a novos produtos e mercados.

Desse modo, já se esperava que as cooperativas com maior patrimônio total fossem as menos diversificadas, uma vez que a maior parte desse patrimônio é notoriamente constituída por ativos imobilizados, o que representa um desestimulante à diversificação ou, visto de outra forma, como estimulante da especialização.

As sobras operacionais (SO) afetam positivamente a probabilidade de diversificação nas cooperativas agropecuárias. Desse modo, um aumento de R\$100.000,00 nas sobras operacionais no fim do período está associado a um aumento de 0,071 na probabilidade de diversificação. 
Conforme já citado, uma das prováveis razões que levam a cooperativa agropecuária a diversificar é o aproveitamento de recursos existentes, sendo a existência de sobras operacionais (SO) fator primordial no estímulo à diversificação.

Quanto ao resultado operacional por cooperado (RO), observou-se que este afeta negativamente a probabilidade de diversificar; assim, um aumento de R\$100.000,00 na RO da cooperativa resultará em diminuição de 5,081 na sua probabilidade de diversificar. Desse modo, pode-se concluir que as cooperativas com maior resultado operacional líquido têm menor probabilidade de diversificar.

Acredita-se que uma empresa enxerga a diversificação como alternativa de diminuição de riscos, quando começa a perder paulatina e sucessivamente a participação no mercado, fato esse aparentemente comprovado, quando se observa que 53\% das cooperativas diversificadas apresentam prejuízo ou baixo retorno no seu negócio principal.

Diante da diminuição dos resultados operacionais por cooperados, devido à queda da receita operacional, ou ao aumento excessivo de custos encargos, o nível de incerteza com relação aos produtos e serviços da cooperativa tende a se elevar e a administração da cooperativa vê a diversificação como meio de retomar o seu poder competitivo no mercado.

\section{Diversificação e Desempenho}

O cálculo do coeficiente de correlação entre grau de diversificação e medidas de resultados financeiros e econômicos nas cooperativas agropecuárias demonstrou que existe associação entre diversificação e as seguintes medidas de resultado ou desempenho: Faturamento Bruto (FB), Resultado Operacional Total (RO), Sobras Operacionais (SO) e Ativo Total (AT).

Conforme pode ser observado no Quadro 2, todas as medidas de resultado ou desempenho foram significativas a menos de $10 \%$ de probabilidade pelo teste estatístico $\mathrm{T}$, com exceção das sobras operacionais, que foram significativas a 10,5\%, sendo, portanto, desconsiderada nas análises subseqüentes. 


\section{Quadro 2: Coeficiente de Correlação entre Diversificação e Medidas de Resultado e Desempenho nas Cooperativas Agropecuárias de MG e SP - 2000}

\begin{tabular}{llllll}
\hline Variáveis & Correlação & Test T & Variáveis & Correlação & Test T \\
\hline Faturamento Bruto & 0,27 & 0,0074 & Resultado Operacional & 0,16 & 0,0483 \\
Ativo Total & 0,31 & 0,0007 & Sobras Operacionais & 0,22 & 0,1056 \\
\hline \hline
\end{tabular}

Fonte: Resultados da pesquisa.

A relação positiva entre diversificação e medidas de resultado, esboçada acima, já foi revelada por outros trabalhos. A esse respeito, citam-se os trabalhos de Menegário e Araújo (2001), Goodhus (1996) e Trechter (1996), que demonstraram que a diversificação afeta positivamente o desempenho das cooperativas agropecuárias.

Os resultados sugerem que, quanto maior a diversificação, acentuadamente melhores serão as medidas de resultado e desempenho nas cooperativas agropecuárias. Daí a contribuição da abordagem da diversificação por uso dos recursos, permitindo identificar também a presença da diversificação entre as maiores cooperativas da amostra, o que se configura como importante elemento empírico dessa abordagem.

O cálculo da correlação por postos veio reforçar os resultados da correlação simples, ao indicar a existência de correlação positiva de 0,25 entre o grau de diversificação e a posição competitiva das cooperativas agropecuárias.

A explicação pode estar na maior abrangência de mercado das cooperativas diversificadas. Assim, a penetração em outros setores pode estar proporcionando, às cooperativas diversificadas, o maior aproveitamento de recursos disponíveis e oportunidades, por meio de uma atitude empreendedora.

Ressalta-se ainda que as cooperativas diversificadas estão menos propensas aos riscos da monoatividade, o que lhes permite conviver melhor com as intempéries do mercado.

Todavia a diversificação não pode ser vista como solução para os problemas de competitividade no setor cooperativista, mas como forma de agregar esforços competitivos dentro da organização. Isso porque se acredita que a competitividade seja influenciada por um universo de fatores, dos quais a diversificação representa apenas um componente.

Ainda assim, os resultados parecem desmistificar a existência de relação 
negativa entre grau de diversificação e competitividade nas cooperativas agropecuárias, conforme postulam os defensores da especialização.

Em síntese, pode-se dizer que a classificação da diversificação como estratégia competitiva é coerente, visto ser possível evidenciar a racionalidade competitiva norteando tal estratégia, o que sumaria a importância do tema dentro da dinâmica competitiva do agronegócio nacional.

\section{Conclusões}

A maior freqüência de diversificação concêntrica representa vantagem competitiva para as cooperativas agropecuárias, uma vez que, de modo geral, lhes permite maior eficiência no aproveitamento dos recursos comuns. O atendimento às necessidades específicas dos cooperados e o incentivo ao desenvolvimento regional, destacados como motivadores da diversificação, vêm destacar o caráter de comprometimento social dessas organizações na formulação de suas estratégias.

Todavia é entre os fatores estruturais que se observaram os condicionantes da diversificação. Dentre eles, o resultado operacional por cooperados, o patrimônio total e o "tipo de cooperativa" relacionaram-se negativamente com a diversificação.

O tipo de cooperativa, um dos principais condicionantes da diversificação, exerce maior influência nas cooperativas mais novas, visto que as cooperativas mais velhas, sobretudo as de maior patrimônio, têm relativa dificuldade de incorporação de estratégia. Isso se dá, em função da existência de ativos específicos e da ótica da especialização como forma de aproveitamento da capacidade ociosa.

Dentre os condicionantes que se relacionaram positivamente com diversificação têm-se a idade da cooperativa, o número de empregados e as sobras operacionais.

O conhecimento da influência dessas variáveis na probabilidade de diversificar se torna importante não apenas para os gerentes e diretores de cooperativas, que poderão fazer uso dessas informações no planejamento estratégico organizacional, mas também para os formuladores das políticas de incentivo e apoio ao sistema cooperativista, que poderão encontrar na diversificação uma das estratégias que visam à elevação dos níveis de competitividade do setor. 
Também parece sensato que a diversificação não seja por si mesma a garantia de bom desempenho, o que aparentemente é uma das justificativas para a diversificação ser bem sucedida em algumas cooperativas e não o ser em outras. Isso se dá porque, além dos recursos disponíveis da região e do mercado específico, a diversificação vai depender também do tipo de produto com que a cooperativa está trabalhando, da sua posição no mercado e da percepção do corpo administrativo acerca das mudanças do ambiente.

\section{Notas}

\footnotetext{
${ }^{1}$ Wood (1971) foi quem introduziu esta classificação com os termos "narrow spectrum diversification" e "broad spectrum diversification".

${ }^{2}$ UEN - Unidade Estratégia de Negócio é uma unidade ou divisão da empresa responsável por determinado negócio ou setor específico, podendo ser composta por marca e administração própria.

${ }^{3}$ Na Teoria da Contingência Estratégica, a diversificação de produtos é vista como uma resposta às contingências, tais como a lei anti-truste, resultados ruins e incerteza sobre as atividades tradicionais da firma (Venkatraman, 1989).

${ }^{4}$ Dentre estes citam-se Gort (1962), Markhan (1973), Montgomery (1985) e Pelepu (1985).

${ }^{5}$ As economias de escopo derivam-se da utilização compartilhada dos insumos. Tal possibilidade de partilha decorre de indivisibilidade ou aglomeração na estrutura produtiva, isto é, diferentes produtos podem exigir praticamente o mesmo investimento fixo (Barni, 1992).

${ }^{6} \mathrm{O}$ valor de $10 \%$ representa uma arbitrariedade necessária, visto que existem casos em que as cooperativas dispõem de pequenos negócios fora de sua atividade principal, ou está apenas iniciando seu processo de diversificação, o que as desqualifica para a análise a que se propõe este estudo.
}

\section{Artigo recebido em 25.03.2003. Aprovado em 18.05.2004.}

\section{RefERÊnCias Bibliográficas}

ANSOF, H. I.

Estratégia empresarial. São Paulo: McGraw-Hill do Brasil, 1977. 203 p.

ARON, D. J.

Ability, moral hazard, firm size and diversification. The Rand Journal of

Economics. Saint Monica, v. 19. n. 1, spring 1988. p. 72-87. 
BARBETTA, P. A.

Estatística aplicada às ciências sociais. 4. ed. Florianópolis: Editora da UFSC, 2001. 338p.

\section{BARNI, E. J.;}

BRANDT, S.A.

Descentralização, diversificação e tamanho de cooperativas agropecuárias. Revista de Economia e Sociologia Rural, Brasília, v. 30, n.1, p. 1-10, jan./mar. 1992.

CARDINAL, L. B.;

OPLER, T.C.

Corporate diversification and innovate efficiency an empirical study. Journal of Accounting and Economics, Rochester, NY, v. 19, mar./ may 1995. p. 365-381.

CRUZ FILHO, H. et al.

Estrutura de custos do comércio cooperativo diversificado. Revista de Economia e Sociologia Rural, Brasília, v.26, n. 2, p. 157-62. Abr./jun. 1988.

DENIS, J. D.;

DENIS, D. K.;

SARIN, A.

Agency problems, equity ownership, and corporate diversification. The Journal of Finance. Berkeley, v. 52, n.1, mar. 1997. p. 135-160.

GOODHUS, R. E.

Agency theory and effort incentives in agricultural cooperatives. American Journal of Agricultural Economics, Stillwater, v. 78, n. 5, mar. 1996.p. 1398.
GUJARATI, D. N.

Econometria básica. São Paulo: Makron Books, 2000. 846 p.

HENDRIKSE, G. W. J.;

VAN OIJEN, A.A. C. J.

Diversification and corporate governance. Rotterdam: Erasmus Universiteit of Rotterdam.2002.10 p. Report Series Research in Management.

MENEGÁRIO, A. H.;

ARAÚJO, P. F. C.

Empregos de indicadores socioeconômicos na avaliação financeira de cooperativas agropecuárias. Economia Aplicada: v. 5, n. 4, out./dez. 2001. p. $757-787$.

MONTGOMERY, C.A.

Corporate diversification. Journal of Economic Perspectives, St. Paul, v. 8, summer 1994. p. 163-178.

NILSSON, J.

Organizational principles for cooperative firms. Scandinavian journal of management. Frederiksberg, v. 17, n. 3, sep. 2001.p. 329-356.

OLIVEIRA, M. M. et alii.

Econometria, Alfragide, Portugal: McGraw-Hill, 1997. 324 p.

\section{PATTISON, D.}

Agricultural cooperatives in selected transitional countries. Disponível em: <Http://www.agricoop.org/ resources/resources.htm>. Acesso em: 18 de aug. 2000. 
PINAZZA, L. A.,

COCAMAR 30 anos de desafios e mudanças. Estudos de caso em agribusiness. São Paulo: Pioneira, 1997.p. 71-96.

PORTER, M. E.

Estratégia competitiva: técnicas para a análise de indústrias e da concorrência Tradução: Elizabeth Maria de Pinho Braga. 7. ed. Rio de Janeiro: Campus, 1986. 362 p.

RAMANUJAM, V.;

VARADARAJAN, P.

Research on corporate diversification: a synthesis. Strategic Management Journal, Purdue University, v.10, nov./dec. 1989. p. 523-551.

ROCHA, E. E. R. B.

O Cooperativismo agrícola em transição: dilemas e perspectivas. 1999. 226 p. Tese (Doutorado em Economia) - Universidade Estadual de Campinas, Campinas.

SANTOS, R. C.

Cooperativa Agropecuária de HOLAMBRA, Estudos de caso em agribusiness, Porto Alegre: Ortz, 1993. p. 127-161.

\section{SEXTON, R. J.}

Cooperatives and the forces shaping agricultural marketing. American Journal of Agricultural Economics. Menasha, dec. 1986. p. 1167-1172.
Imperfect competition in agricultural market and the role of cooperatives: a spatial analysis. American Journal of Agricultural Economics, Menasha, v. 72, n. 3, aug. 1990. p. 709-720.

TACHIZAWA, T.;

REZENDE, W.,

Estratégia empresarial: tendências e desafios, São Paulo: Makron Books, 2000.193 p.

\section{TEECE, D.J.}

Towards an economic theory of the multiproduct firm. Journal of Economic Behavior and Organization, James Madison University, v.3, mar. 1982. p. 39-63.

\section{TRECHTER, D. D.}

Impact of diversification on agricultural cooperatives in Wisconsin, Agribusiness, v. 12, n. 4, 1996. p. 385-394.

\section{VENKATRAMAN, N.}

The concept of fit in strategy research: toward verbal and statistical correspondence. Academy of Management Review, n.14, 1989. p. 423-444.

WOOD, A.

Diversification, merger and research expenditures: a review of empirical studies. In: MORRIS, R.; WOOD, A. (Ed.), The corporate economy: growth, competition, and innovation potential. Cambridge: Harvard University Press, 1971. p. 115-145. 